\title{
Construction and Application of Practical Teaching Model for Food Quality and Safety Specialty
}

\author{
BAO Bin, WANG Xichang, NING Xibin, CONG Jian, LIU Yuan, DING Zhouping, ZHONG Yaoguang, \\ LI Xiaohui, YI Jierong \\ College of Food Science and Technology, Shanghai Ocean University, Shanghai, China, 201306 \\ bbao@shou.edu.cn
}

\begin{abstract}
Connotation and extension of practical teaching mode were thought about after seven year-practice of specialty construction for Food Quality and Safety in Shanghai Ocean University. Omni-bearing and multi-layer practical teaching system was constructed, within which practical teaching methodology was explored, and teaching standard and quality were upgraded. More students with practical capability and innovative spirit were cultivated and have become talents in the fields of food analysis, safety assessment, quality management and quality control.

Index Terms - Practical teaching; food quality and safety specialty; construction
\end{abstract}

\section{Introduction}

Practical education is an important component of college education and teaching. "Teaching Quality and Teaching Reform Project for Bachelors' Education with Tertiary Schools" as launched by Ministry of Education in 2007 expressly advocated that higher education shall cultivate senior and specialized talents with innovative spirit and practical capacity; the National Medium to Long Term Education Reform and Development Planning Outline also proposed that the talent cultivation with higher education shall "strengthen practical teaching". Practical education/teaching is a critical link for cultivating the innovative spirit and practical ability for college students, and is important carrier for cultivating the professional quality and practical skills. Practical education plays irreplaceable role in cultivating the application ability of students and boosting the employment competitiveness of students. For application discipline such as food quality and safety, the training of practical ability is of important realistic meaning.

According to the requirement by state and society on talent cultivation, after seven years' teaching practices, we have kept exploring, practicing and elaborating the practical teaching model of food quality and safety specialty, and have built up the all round and multiple-level practical education system including course experimentation, teaching internsh ip, innovative practice, graduation thesis and social practice.
Comprehensive and strict practical training was delivered for our students, and remarkable teaching performance was achieved.

\section{Building and Application of Practical Education Model for Food Quality and Safety Specialty}

\subsection{Course Experimentation}

According to the teaching program for food quality and safety specialty 2010, the experimental courses and class hour and credit hour statistics are in Table 1. In the discipline education module, six courses are provided with experimental teaching, with 176 class hours. The ratio between experiment class hours and theoretical class hours is higher than 1:2, and the ratio between experimental credits as mandatory and the minimal credits as mandatory in this module is 1:9. The configuration of experimental teaching lays down solid foundation for experimental skills for study of specialized courses. In specialized education module, 12 courses are provided with experimental teaching, with 198 class hours in total. The ratio between experimental class hours and theoretical class hours also exceeds $1: 2$, and the ratio of experiment credits as mandatory versus minimal credits in this module is 1:5.4. The food microbiology experiment, instrument analysis experiment, gene-engineering experiment, food toxicology experiment, food physiochemical inspection technique experiment, food safety science experiment, food adulteration inspecting experiment, food nutrition experiment and food chemistry experiment constitute the all round and comprehensive experiment system for specialized courses of food quality and safety specialty. Compared with the experiment teaching for food quality and safety specialty in other universities in China, the experiment courses in our university are richly arranged and have higher class hour ratio. Experimental teaching is fully guaranteed from education program. 
Table 1. Statistics on courses and class/credit hours for experimental teaching for food quality and safety specialty

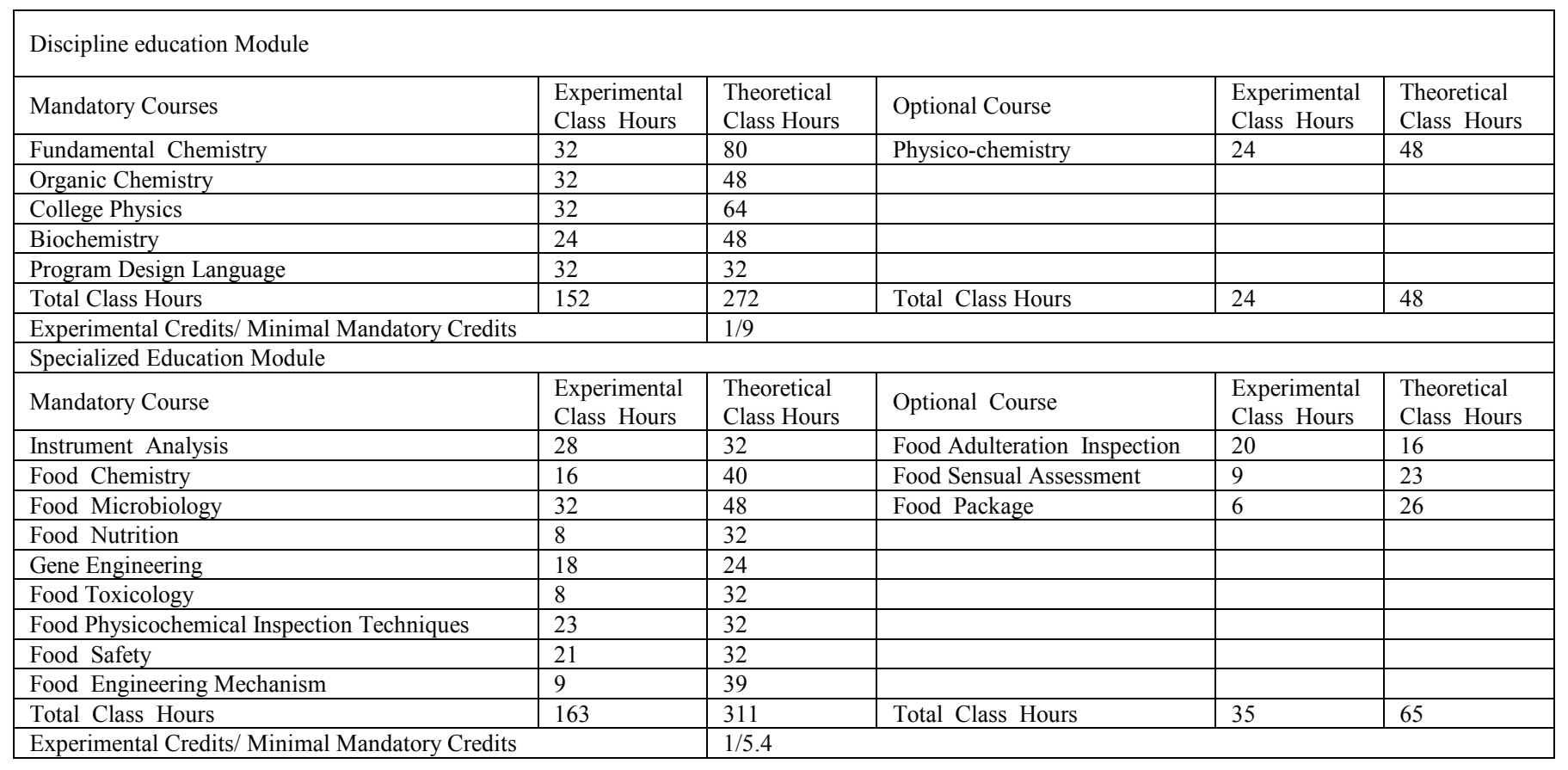

\subsection{Internship for Education}

Now the multi-tiered internship system with distinct discipline feature for food quality and safety specialty is taking shape, and the characteristics of entire internship system are systematic, diversified, progressive and penetrating.

With regard to the junior students, we arrange cognition internship, with main scope as visiting foodstuff plants, government inspection authority and expert workshop. Students are enabled to have a preliminary understanding on enterprise production and quality control before they take specialized courses, which are helpful for their specialized course study, and by which discipline understanding of the students is strengthened. As to senior students, they have studied the main specialized courses, so food processing practice and food quality evaluation practice that are closely related with specialized courses are offered. Food processing practice covers mostly preparation of yogurt, cake, fish-ball, and mayonnaise, and jam, etc. In addition the students may choose bread preparation; the food quality evaluation practice mostly covers rapid inspection of vibrio patahaemolyticus, sensual and physiochemical assessment for meat, and meat flavor identification, etc. Through practice, the students may integrate the theories with practice, and upgrade the practical capacity. For senior student to be graduated, graduation internship is arranged. Students can be interns for six weeks at professional internship base related with food quality and safety, and attend the jobs and work arrangement of relevant company/entity, and accept comprehensive training for practical ability before they graduate from college.

\subsection{Innovation Practice}

In recent years, the students of food quality and safety specialty attended multiple innovation practice projects organized by Shanghai municipal government and college, such as Shanghai College Student Innovation Activity Program, Shanghai Ocean University LUO ZHAOYAO College Student Science and Technology Innovation Project, American Big Almond Innovation Competition, Danisco Cup "Nutrition and Health" Student Competition, Summer Instant Noodle Innovation Competition, Novozymes "Application of Enzyme in Food Industry" Innovation Competition, Laiyifen Leisure and Taste Innovation Competition as science and technology innovation activities. Many students conduct innovation experiments at professional laboratory of food quality and safety specialty. Such innovative practical activities encouraged the innovative spirit and participation awareness among students, triggered the food development thinking of students, developed the independent innovative capacity of students, and built effective platform between theoretical research and practical application.

\subsection{Graduation Thesis}

For four consecutive years beginning from 2004 to 2008, altogether 538 graduates from our food quality and safety specialty had completed their graduation thesis at research labs in our college, related enterprises, companies, and research institutes in Shanghai. Each student was given one topic, covering different sectors in food quality and safety specialty. According to the education program, the last semester of senior year is for graduation thesis, some outstanding students would select research labs in their junior 
year, and take part in the research and development (R\&D) project of lecturers, and complete their graduation thesis in the mean time. Through the graduation thesis, students gain comprehensive professional training before graduation, covering literature search, translation of English literature, write-up of literature review, design of experimental plan, completion of all the experiments and composing graduation thesis, and defense of their graduation thesis. The practical ability and innovative spirit of students are fully exercised, demonstrated and sublimed.

\subsection{Social Practice}

The students of food quality and safety specialty are accessible to rich social practice opportunities during the four years study, such as the once a year food safety publicity week, community services by Scientific Volunteer Service Society (Science Store) of Shanghai Ocean University, who will deliver consultancy, workshops, and inspection services for food safety, food nutrition and health. The student will set up research projects concerned by community residents. Through these activities, on the one hand a platform is created for citizens to access food safety knowledge; on the other hand it enables the students to serve the citizens and residents with their theoretical knowledge learned in class. Moreover students exercise their capability of communication, practice and research in these serial activities. In addition to regular social practice, during Expo Shanghai, 35 students were selected for internship with Shanghai Food and Drug Administration (FDA) Expo, to offer professional service for food safety of Expo. The practical abilities of students are exercised and boosted in those social practices, laying down foundation for them to join the society and engage in all sorts of jobs.

\section{Innovation of Practical Teaching Model for Food Quality And Safety Specialty}

\subsection{Build-up of Teaching Resources for Practical Education}

3.1.1. Setup of practical teaching team that is all round and multi-leveled. High level practical teaching team is the fundamental guarantee for quality of practical teaching. The practical teaching team of food quality and safety specialty includes the experimental lecturers, professional lecturers of college, and the teachers of internship base with rich practical experience. In experimental teaching process, our professional teachers from professors to young lecturers are all participating in the experimental teaching of this specialty. In the teaching internship, in addition to the internship led by professional lecturers, social resources are fully leveraged to strengthen practical teaching. For example, in graduation internship, teachers of the entities that offer internship are appointed to be the supervisors of students. At each internship entity, the students get "one to two" even "one to one" supervision by teachers from the internship entity; the teachers will teach the students in hands on the content of all the scope of the internship. The students will complete and understand dexterously all the experimentation with teacher's supervision.
In cognition internship, in addition to visiting enterprises, inspection institutes and $\mathrm{R} \& \mathrm{D}$ institutes, leaders of government, known experts of companies, principals of institutes, and experts of practical departments are invited to provide professional workshops and seminars to students, in order to upgrade the professional cognition capacity of students.

3.1.2. Cultivation of practical teaching team. With regard to inadequate experience of young lecturers who went straight from university to our university, the college encourages young lecturers to work temporarily with companies or public agencies in vacations, in order to upgrade their practical teaching level. In last two years, the college assigned six young lecturers to work temporarily with Shanghai FDA and Shanghai Food Institute. Meanwhile young lecturers shall participate in the innovative projects and social practice of students as supervisors. In this process the professional teachers can serve the society with their expertise, and more important is that the lecturers can understand social demand and upgrade their practical teaching ability in these social practices. In addition, the college has assigned several lecturers for training at home and aboard, e.g. participation in "Food Safety Specialty Lecturer Training" sponsored by Australian government, with the scope of training involved administration of corporate food quality and safety, practices for food safety risk assessment. Lecturers are selected and assigned to training of "Food Safety Operator" by state and Shanghai, and training for nationally registered auditors for food safety management system. After such training and exercise, the practical experience of lecturers is significantly upgraded that lays the foundation for boosting the practical teaching level.

\subsection{Reform of Practical Teaching Scope}

3.2.1. Reform of practical teaching scope according to social demand and feedback. In order to keep upgrading the practical ability of students, in the seven yea teaching process, we have kept reforming the scope of practical teaching according to social demand and feedback of students and internship units, and practical teaching was strengthened. At first, due to the adulteration of food in society, two specialized experiment courses were added, i.e. gene engineering and food adulteration inspection technology, which enable the students to master mechanism and experimental technologies to quickly identify the food adulteration, and are adaptive to the social demand for students. Secondly, "Food Processing Practices" and "Food Quality Evaluation" of two weeks were added, through which students are helped to apply the theoretical knowledge in "Food Processing", "Food Preservation" and "Food Package Science" learned in junior year to practice. According to the feedback by internship base that "graduation internship is too short and the study of students with internship units was not in-depth enough", previous "graduation internship" was transferred to senior year after completion of specialized courses, and the duration was extended from previous four weeks to six weeks. Through this adjustment, 
the students can rather completely study and participate in one or several works of internship unit, enabling the students to take comprehensive training for practical ability of specialized knowledge before going out of school. Finally the job market need is considered when developing off-campus internship base. At present, due to the attention on food safety inspection from state to local government, many third party inspection institutes urgently need graduates from food quality and safety specialty, so when we were extending the off-campus internship base, we contacted with some third party inspection institutes in Shanghai. Students are able to be interns at such bases, with the experience of working in the third party inspection institute. On the one hand these students may become the reserved resources of the internship unit, and may be recruited as official employees; on the other hand this internship experience can become a plus for them to be employed by other third party inspection organizations.

3.2.2. Improvement of the conditions of practical teaching and elaboration of the practical teaching content. With several investments by Shanghai Municipal Education Commission and the university, the experimental teaching conditions of food quality and safety specialty are improved considerably. 17 new experiments were set up, and nine experiments were improved. Compared with the experimental teaching scope with food quality and safety specialty of other domestic universities, our experimental courses are rich, covering all the aspects of food quality and safety specialty. As to buildup of internship bases, we have established 12 offcampus internship bases, covering food enterprises, food safety inspection organizations, government agencies for food safety administration. The demand for cognition internship and graduation internship of students can be satisfied. For buildup of on-campus internship base, we keep extending the vision, and establish the on-campus internship base together with the university logistic service center, which offers processing internship and quality management internship for bakery food for students. Part of the research labs are leveraged as on-campus internship bases for students, such as food quality evaluation lab, enabling students to use large scale instruments such as electronic nose and GC-MS, to assess the meat quality by change in meat flavor.

3.2.3. Instillation of new connotation into practice teaching by innovation practice and social practice. All the college student innovation activities by Shanghai municipality and the university, the community service by Scientific Volunteer Service Society (Science Store) of Shanghai Ocean University, and internship of Expo FDA food safety interns are open and practical, and are closely related with social demand and professional practical skills, which instill new connotation for practical teaching, and upgrade the professional cognition and practical ability of students. E.g. during the Expo, students followed supervisors from Shanghai municipal FDA to conduct food safety inspection at all the catering sites at Expo Park. The students learned to use the latest rapid inspection instruments, and practiced the food safety administration for large international event.

\subsection{Exploration of Practical Teaching Model}

3.3.1. Adoption of project teaching method and experiencing teaching method. According to modern education theory, knowledge is not instilled by lecturer, and is instead obtained by interaction of students with surrounding study environment, and by the active thinking and exploration of students, with the instruction and help of teacher. In the practical education process, we select project teaching method ${ }^{[1]}$ and experiencing teaching method ${ }^{[2]}$ that fit for practical education. For example in food processing practice, in addition to nine practice projects as mandatory projects, students can choose one optional project according to their interest. In the practical process for one week, students shall design the practical scope of these projects covering practice procedure, process parameters and formulation, then conduct processing practice, assess the finished products, explore the flaw in design, improve the practice, till successful product is made. Through such experiencing teaching, the students will not only process food, but also have deeper and wider understanding for theoretical knowledge of processing.

3.3.2. Application of enlightening and problem-based teaching method in practical teaching. In practical teaching process, traditional teaching method of instillation and operation according to textbook has been changed, and advanced teaching model of enlightening and problem-based teaching method are adopted to trigger the active thinking of students. Processing and storage practice is extension of food processing science and food preservation course. If the contents were simply listed in the internship guideline, the students will be passive in preparation and drafting internship report. How to motivate the students for active thinking and recalling the knowledge in classrooms before processing practice, how to prompt the students to look up the textbooks and literature and conduct preparation before internship? We raise questions about process operation, process parameters, impact factors and tips when composing the internship guideline, which are sent to students in soft copy before internship. Students are required to think and prepare according to the questions before internship, and these questions are to be noted by students during internship.

\subsection{Trial for Reform of Practical Courses Performance Assessment}

In the assessment of processing and quality evaluation practice and graduation internship, we take competitive defense as makeup for the previous assessment model, which was mostly based upon attendance, internship attitude, internship log, and internship report to assess the internship score. Now higher requirement is raised for students who performed outstandingly in internship and intent to obtain A grade. The teaching idea of this model is that education should be conducted according to the aptitude of students, and should manage according to students'performance. When a students have more space to achieve more, their score management shall be distinguished from others students. Two objectives are to be achieved through competitive defense. Firstly internship 
report is the description for each specific item in internship, while competitive defense is the distillation and summarization of entire internship process by students, and is the sublimed version of internship report. Good students can exercise their summarization and expression ability through competitive defense. Another more important objective is to set up a platform of summarization and exchange for internship experience. Students may learn from each other, and teachers may timely find out problems during internship, which would be corrected and improved next time.

\subsection{Reform of Practical Education Management}

3.5.1. Integration of the teaching laboratories and efficient running of the specialized laboratories. Compared with fundamental course laboratories, the difference of specialized laboratories is that more experimental courses are to be arranged in laboratories, with less experimental class hours and less classes. Now the bachelors' teaching experimental venues of food quality and safety specialty offer six experimental courses for food quality and safety specialty, food science and engineering specialty, package engineering specialty and food logistic engineering specialty, and the experimental teaching assignments for 25 classes every year, and also serve as the premises for food processing practice and food quality evaluation practice for students of these specialties in summer semester. If the traditional laboratory teaching management model, one lab for one course, is adopted, then six labs are needed, on the other hand if six labs are provided, then the efficiency of each lab is not very high. According to the available two labs provided by college, we have integrated the lab resources, stored the glassware and instruments needed by six experimental courses by type. Before each experiment course is opened, the grouped instruments are placed by group on bench from the storage, and withdraw them after completion of experimentation. So one lab can offer three experimental courses, while meeting the demand of innovative experimentation and summer semester practices. Each lab is running at full capacity each semester, and such model offers some successful experience for efficient use of specialized laboratories.

3.5.2. Seizing the critical link in practical teaching management and conducting effective practical teaching management. In the management process of practical teaching, we conduct effective teaching management by seizing all the critical links in practical teaching, and guarantee the quality of practical teaching. In previous teaching outline, the experimental content was attached to the theoretical courses syllabus. After the revision of Teaching Outline 2010, each experimental course has separated syllabus. Students are required to write up pre-study report to reduce the blindness in experiment process before the experiment class. After completion of experiment, experiment lecturer and specialized lecturer shall summarize the experiment management in this semester to identify the concerns, in combination with student feedback, which shall serve as the basis for modification and improvement for experimental projects. For example, students fed back that the spectro- photometers in lab were not enough, which affected the experimental process, so in the college procurement, we gave priority to buy six spectrophotometers, plus the four existing, now less than two groups of students sharing one of them. For teaching internship, we require teacher to draft internship syllabus, and write up internship instructions. Internship plan shall be drafted before internship, with summarization after internship. For graduation thesis, there are requirements by university at all critical links, such as selection of topics by students, formulation of assignment paper, mid-term check, write-up requirement for graduation thesis, and defense requirement, etc. We need to implement all the links according to school requirements and ensure the quality of graduation thesis.

\section{Teaching Performance of Practical Teaching Model of Food Quality and Safety Specialty}

In last seven years, we keep exploring and elaborating practical teaching model, in order to make practical teaching a platform for promoting students learning, upgrading the interest of study, boosting the practical ability, and forming employment advantage.

\subsection{Expectation by Students}

Food processing and quality evaluation practice is richly arranged. Practical projects are integrated with class teaching, and students are provided with hands-on and highly operable experience, so students are quite interested and looking forward to internship. For example the bread preparation at cake shop, the students prepare the breads according to the pattern they designed. After internship they can eat bread by their own, with jam they produced, drink yogurt produced by them. Students can also prepare mayonnaise for decoration of fancy breads. These edible study achievements further promote students understanding and being keen on the specialty.

\subsection{Gain for Students}

By evaluation of the quality of product prepared, students may judge the success and failure in the preparation process. In case of failure when producing mayonnaise and yogurt, lecturer and students will jointly discuss the cause of failure, and consolidate the knowledge learned in this process. For example, the material adding sequence will impact the formation of emulsion of mayonnaise, while the stir in fermentation process may impact the growth of lactobacillus. In the competitive defense process, students will summarize the same internship from different views. Some students will focus on analyzing the causes of failure, while some students will emphasize on factors affecting the product quality. The students will interact by question and answer, and learn from each other.

\subsection{Advantage for Students}

After graduation internship for six weeks, the students were transformed from the nervousness on initial using of 
large scale instruments to confidently explaining the structure, use and tips of these instruments to lecturers. Such internship will give them some edge in experience in employment, which will be eventually translated into advantage in job market.

After reform and practice for a couple of years, the practical education system for food quality and safety specialty has become a model of all round and multi-level. This model is provided with comprehensive practical teaching contents, advanced practical education facilities, teaching ideas and methodology, as well as efficient practical teaching management. In future, more professional talents with strong practical abilities and innovative spirit would be cultivated for the nation and society. Food quality and safety specialty in our college would become an important base for high level talent cultivation, food quality and safety $\mathrm{R} \& \mathrm{D}$, and joint research and academic exchange between China and international community.

\section{References}

[1] Zhou L, Song J Practical Teaching Methodology: Exploring the New Path for Practical Education Occupational Education Exploration and Research (3), 18 (2005)

[2] $\mathrm{Wu} \mathrm{H}$, Liu T Application of Experiencing Teaching Methodology in Cultivation of Applied Talents in International Trade Specialty Information of Science and Technology (4), 25 (2005)

[3] Li S Application of Enlightening Teaching in Field Practical Education Beijing Education (Tertiary Education Version) (Z1), 62 (2009)

[4] Kong W, Liu Y, Xue F, et al Discussion on Implementation for Q\&A Teaching in Higher Education Heilongjiang Medical Science 36 (4), 306 (2012) 